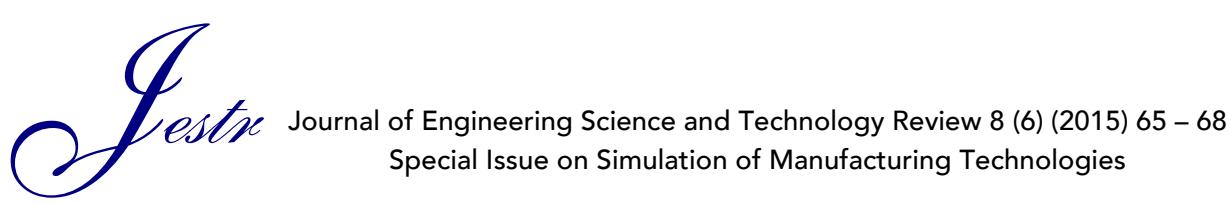

Conference Article

\title{
Computer modelling of the effect of clamping in linear friction welding
}

\author{
A.M. Yamileva ${ }^{1}$, R.K. Gazizov ${ }^{1}$ and A. Vairis ${ }^{2}$ \\ ${ }^{1}$ Ufa State Aviation Technical University, Ufa, Russia \\ ${ }^{2}$ Technological Educational Institute of Crete, Estavromenos Iraklio Crete, Greece
}

Received 2 September 2015; Accepted 12 September 2015

\begin{abstract}
A two-dimensional FE model of the equilibrium stage of linear friction welding, using ANSYS Mechanical, was developed. The qualitative influence of the clamp location on temperature and stress fields was investigated. It was shown that the fixing location has a significant effect on heat generation and, as a consequence, temperature distribution.
\end{abstract}

Keywords: Linear friction welding, finite element method, ANSYS Mechanical.

\section{Introduction}

In its ever lasting pursuit of advancement aviation industry explores new technologies to manufacture a new generation of gas turbine engines (GTE), to satisfy the demands of increasing thrust per pound of weight. One of such technologies is linear friction welding (LFW) to manufacture GTE blisks instead of milling them from solid blanks. Moreover, LFW allows to replace individually damaged blades instead of replacing the whole blisk.

During LFW a joint between parts is formed by applying a compressive force to them while welded parts are moving in a reciprocating mode relative to each other.

There are many papers on LFW of titanium alloys, such as Ti-6Al-4V [1, 2, 3, 4]. But more recently there is strong interest in LFW to use with other materials, like aluminum alloys and composite materials [5, 6, 7]. There are significant differences expected in the characteristics of the process between titanium and aluminum alloys. So it is important to study these materials with computer modeling.

As published literature shows, there should be uniform distribution of temperature along the weld line for a sound joint to be produced. In order to obtain the uniform distribution of temperature along the weld line there are a number of factors to consider which affect welding, such as the amplitude and frequency of oscillation, applied pressure etc. The location of the clamp, and in particular the fixing height has a considerable effect on the temperature and stress fields.

In this work the effect of fixing height was studied using a simplified computer model of LFW. Results of simulation for titanium and aluminum alloys were compared.

*E-mail address: a.yamileva@gmail.com ISSN: 1791-2377 @ 2014 Kavala Institute of Technology. All rights reserved.

\section{Finite Element model of LFW Process}

A two-dimensional model was developed which had two rectangular samples with a size of $26 \mathrm{~mm} \times 35 \mathrm{~mm}$. The upper sample was constrained horizontally, while the lower one oscillated in sin-like manner with an amplitude of $2 \mathrm{~mm}$ and frequency of $50 \mathrm{~Hz}$. Samples are also compressed under a pressure of $100 \mathrm{MPa}$ which is applied on the top edge of the upper sample. The bottom edge of the lower sample is fixed in the Y-axis direction.

The duration of the modeled process was taken to be 0.1 seconds which is adequate for a relatively quick estimation of stress and temperature fields. The aluminum alloy A2024 and titanium alloy Ti-6Al-4V were used in the model. Due to the short run, the material model is considered to be elastic and non-dependent on temperature. (Table 1). The coefficient of friction was taken as constant, same for both materials to eliminate its effect on the results.

The initial temperature of samples is uniform and equal $293 \mathrm{~K}$ (room temperature). The process is considered adiabatic due to the short run.

Table 1.Material properties using in simplified model of LFW

\begin{tabular}{lcc}
\hline & $\begin{array}{c}\text { Aluminum } \\
\text { alloy A2024 }\end{array}$ & $\begin{array}{c}\text { Titanium alloy } \\
\text { Ti-6Al-4V }\end{array}$ \\
\hline Young modulus, GPa & 68.9 & 115 \\
Poisson ratio & 0.33 & 0.31 \\
Density, kg/m3 & 2700 & 4450 \\
Heat capacity, J/(kg K) & 900 & 580 \\
Thermal conductivity, W/(m K) & 180.2 & 8.37 \\
$\begin{array}{l}\text { Thermal expansion coefficient } \\
\text { (ref. temp. 293 K), 10-6K-1 }\end{array}$ & 22 & 8.4 \\
Friction coefficient & 0.3 & 0.3 \\
\hline
\end{tabular}



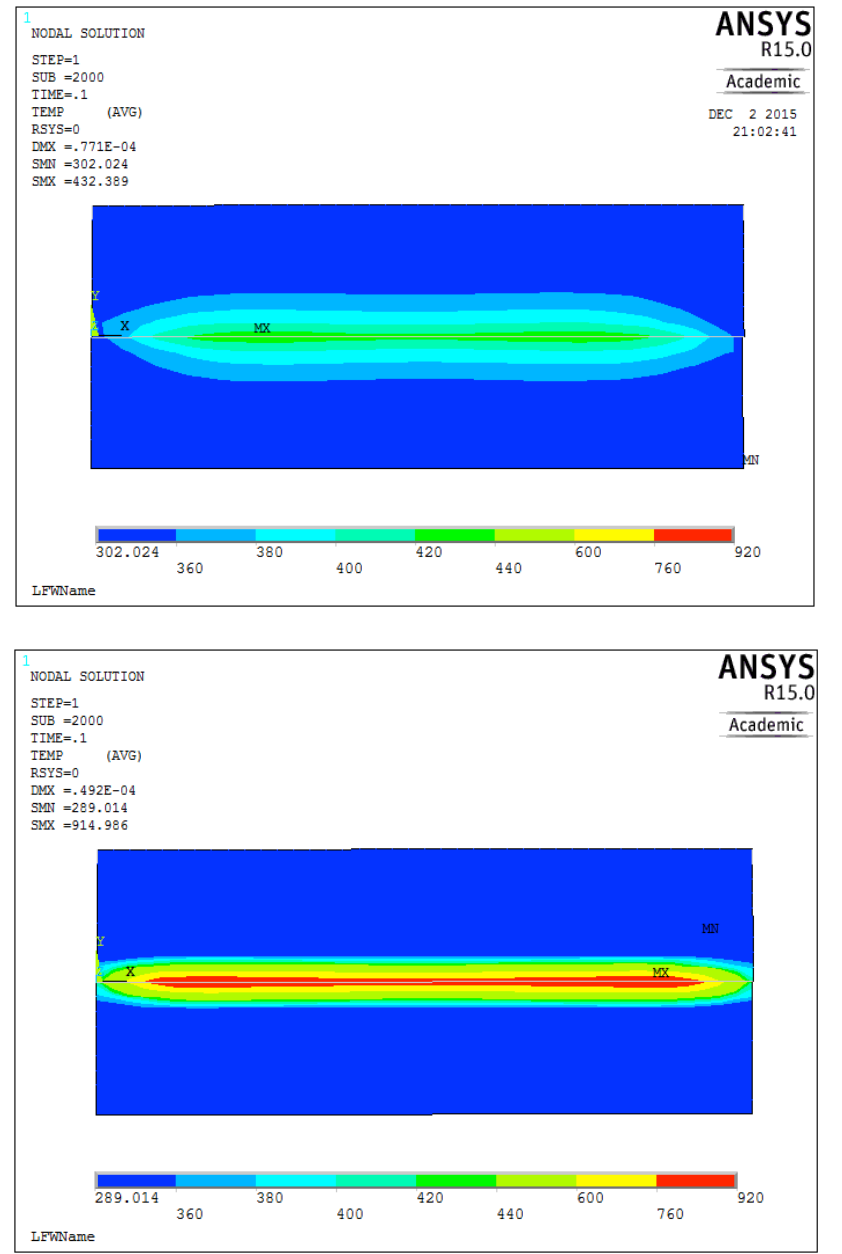

Fig.1. Temperature field in the contact zone after $0.1 \mathrm{~s}$ for Al (upper) and Ti (lower) alloys

Temperature and stress fields were obtained as a result of computer simulation with ANSYS Mechanical software. The temperature distribution along the contact line is similar for both materials as Figure 1 shows although at different values. The maximum value is near the center. But for aluminum alloy width of heated zone is bigger than in titanium alloy due to higher thermal conductivity.

Figure 2 shows the distribution of von Mises stresses near the contact area. The upper sample is moving from left to the right at that instance that the picture is depicting. There is a qualitative agreement of the plots for both materials. In the case of the aluminum alloy the maximal value of stress is lesser than that of titanium, whereas stresses at 3-5 $\mathrm{mm}$ above and below the contact line are higher. So stress gradients in titanium are larger and yielding begins at the contact zone. For aluminum high stresses also developed near the clamp which may cause plastic deformation at the specimen fixing points during the whole process.

Therefore when modeling LFW of an aluminum alloy it is necessary to consider not only the area at and near the welding line, but the whole sample. It would be also preferable to obtain a more uniform distribution of temperature along the contact line before warming a significant part of the specimen.
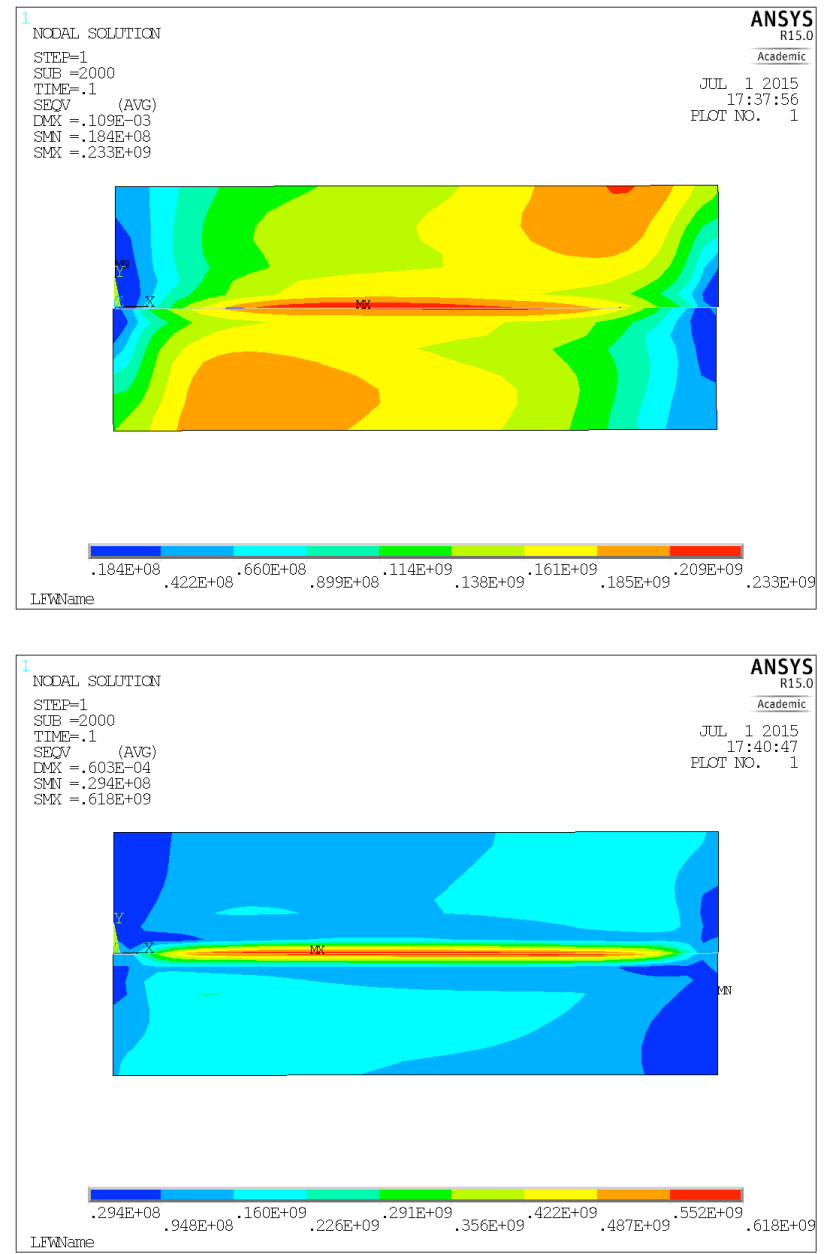

Fig.2. Von Mises stress field in the contact zone after $0.1 \mathrm{~s}$ for $\mathrm{Al}$ (upper) and $\mathrm{Ti}$ (lower) alloys.

\section{Qualitative analysis of the fixing height on temperature and stress fields}

The fixing height $\mathrm{H}$ is introduced in the sample without fixing (Figure 3). Estimations using the FE model with different values of $\mathrm{H}(5-25 \mathrm{~mm})$ were performed. It allows to estimate the dependence of heat generation on the fixing height due to differences in contact pressure distribution.

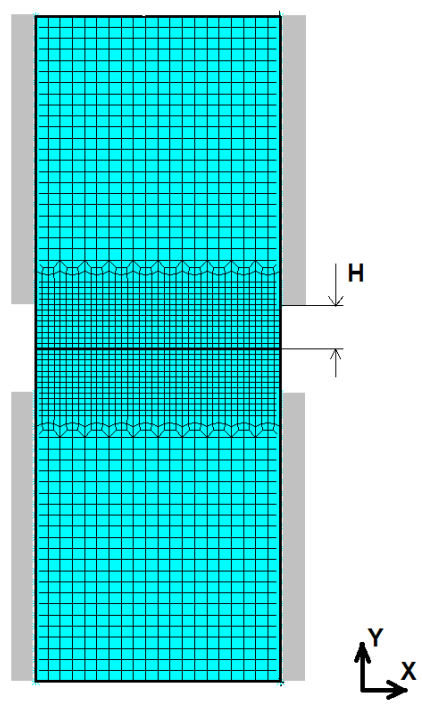

Fig.3. Changing fixing length $\mathrm{H}$ with free end of specimen 

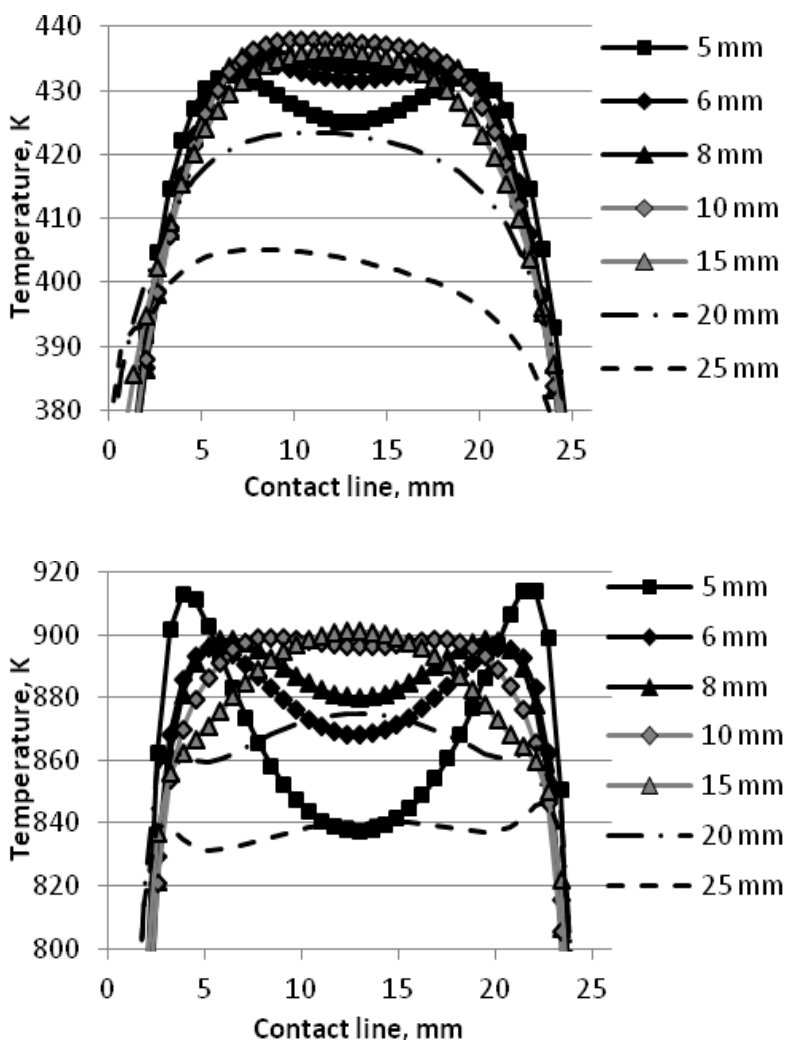

Fig.4. Temperature field on the contact line at the time $0.1 \mathrm{~s}$ for different values of $\mathrm{H}$ for $\mathrm{Al}$ (upper) and $\mathrm{Ti}$ (lower) alloys

Changing of $\mathrm{H}$ has non-linear character: at the beginning it leads to more intensive heat generation, larger temperatures and decreasing of temperature gradients in the center of the weld line for both alloys (Figure 4). But when $\mathrm{H}$ exceeds some critical value, we can observe decreasing of maximum temperature in a weld line and its distribution becomes more flat (see Fig. $4 \mathrm{H}=20 \mathrm{~mm}$ and $25 \mathrm{~mm}$ ).

When $\mathrm{H}$ increases from 5 to $10 \mathrm{~mm}$, two maxima in the temperature field develop. For an $\mathrm{H}$ of $15 \mathrm{~mm}$ the temperature distribution comes close to a parabolic one with a maximum at the center. With further increase of $\mathrm{H}$ temperature decreases while remaining parabolic in shape for the aluminum alloy. In the case of titanium alloy two additional maxima developed which are at $3 \mathrm{~mm}$ away from the edges. For $\mathrm{H}=25 \mathrm{~mm}$ the maximum at the centre almost disappears and the other maxima become pronounced.

It should be noted that for a large $\mathrm{H}$ the temperature distribution is not perfectly symmetrical: with local maxima not located at the center, but closer to the edges of the samples. In all cases temperature gradients remained low.

The effect of $\mathrm{H}$ on the stress field is significant only along the vertical axis of the samples (Figure 5).

For titanium, the maximum value of stresses is reached in an area near weld line, and this value is much greater than a stress level in samples bulk. In other words, the gradient of stresses in titanium samples exists only near weld line: stress level decreases for $400 \mathrm{MPa}$ along a distance of 1-2 $\mathrm{mm}$ from weld line into bulk of sample. Then, after this minimum, value of stresses start to increase and its' behavior strongly depends on $\mathrm{H}$ : as $\mathrm{H}$ increases, as stress level increases too.

In the case of the aluminum alloy stresses reach a maximum value of about $250 \mathrm{MPa}$ on the contact line, which is not much larger for large $\mathrm{H}$ (15-25 mm). For small
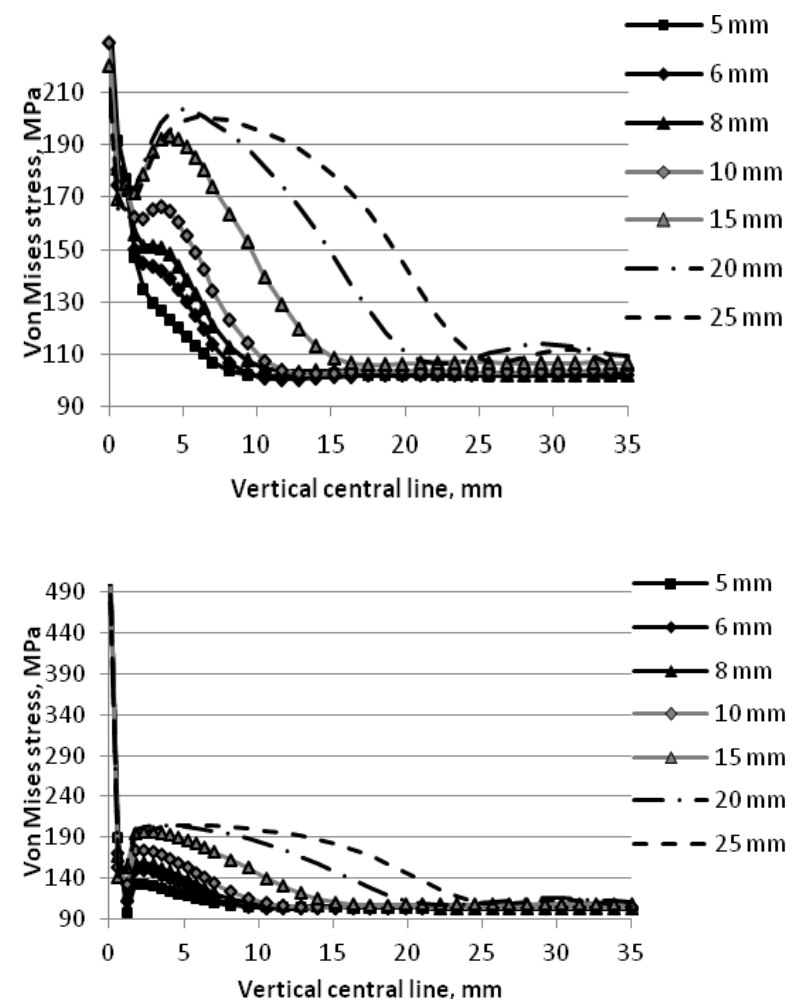

Fig.5. Stress field on the vertical central line at the time $0.1 \mathrm{~s}$ for different value $\mathrm{H}$ for $\mathrm{Al}$ (upper) and $\mathrm{Ti}$ (lower) alloys.

values up to $10 \mathrm{~mm}$ stress distribution is monotonic without a local minimum. But for values of $\mathrm{H} 10-25 \mathrm{~mm}$ there is a local minimum like in titanium, but at a smaller gradient. Thus, a low value of $\mathrm{H}$ (up to $10 \mathrm{~mm}$ ) is preferable to avoid high stresses near the clamp.

\section{Conclusions}

Modelling of the elastic phase of linear friction welding of the titanium alloy Ti-6Al-4V and the aluminum alloy A2024 was performed using ANSYS Mechanical. There was a comparison of modeling results for both alloys.

It was shown that fixing location has a significant effect on heat generation and, as a consequence, temperature distribution. Changing the fixing height by $2 \mathrm{~mm}$ gives large qualitative and quantitative differences in the temperature and stress field for both materials.

For the titanium alloy fixation at $10 \mathrm{~mm}$ of free length is preferable to avoid gradients in the middle of the contact zone and to provide symmetry in the stress and temperature fields which will produce a uniform output of flash.

The aluminium alloy is more forgiving allowing a wider range of fixing height $(6-15 \mathrm{~mm}$ in this model) for a uniform distributions of temperature along the contact line. Therefore, further studies are necessary to determine the position of the clamp. Note that this is especially important for aluminum alloys because of the limited number of experimental data of sound LFW joints. 


\section{Acknowledgments}

The results of this work were produced during the joint project between USATU (Ufa State Aviation Technical University) and UMPO (Ufa Engine Industrial Association) titled "Elaboration and industrial development of highprecision shaping coordinated technologies and superficial hardening of responsible details from Al-alloys with heightened constructional energy efficiency", implemented under the contract №40/10-30976/NCh-NCh-01-13-HG sponsored by the Ministry of Education and Science of the Russian Federation (contract №02.G25.31.0010 between UMPO and the Ministry of Education and Science of the
Russian Federation) through the Resolution of the Russian Federation Government No 218 from April 9, 2010.

This work also partially was supported by grant of the Government of Russian Federation through Resolution No. 220, Agreement No. 11.G34.31.0042.

\section{References}

[1] A.Vairis, M.Frost. "On the extrusion stage of linear friction welding of Ti6A14V", Material Science and Engineering, A271, pp. 477484, 1999.

[2] A. Vairis, "Superplasticity Effects and Strain Rate Dependency in a Material Joining Process", Journal of Engineering Science and Technology Review, vol.1, pp.28-32, 2008.

[3] J. Sorina-Müller, M. Rettenmayr, D. Schneefeld, O. Roder, W. Fried, "FEM simulation of the linear friction welding of titanium alloys", J. Computational Materials Science, vol.48, pp.749-758, 2010.

[4] R. Turner, R.M. Ward, J-C. Gebelin and R.C. Reed, "Linear friction welding of Ti-6Al-4V: Modelling and validation", Acta Material, vol.59, issue.10, pp. 3792-3803, 2011.

[5] X. Song and others, "Residual stresses in Linear Friction Welding of aluminium alloys", Materials and Design, vol.50, pp. 360-369, 2013.

[6] F. Rotundo, A. Morri, L. Ceschini, "Linear Friction Welding of a 2024 Al Alloy: Microstructural, Tensile and Fatigue Properties", Light Metals, pp. 493-496, 2012.

[7] F. Rotundo, A. Marconi, A. Morri, A. Ceschini, "Dissimilar linear friction welding between a $\mathrm{SiC}$ particle reinforced aluminum composite and a monolithic aluminum alloy: Microstructural, tensile and fatigue properties", Materials Science \& Engineering A, vol.559, pp. 852-860, 2013. 